\begin{tabular}{|c|l|}
\hline Title & Accelerated pacific plate subduction following interplate thrust earthquakes at the Japan trench \\
\hline Author(s) & Heki, Kosuke; Mitsui, Yuta \\
\hline Citation & $\begin{array}{l}\text { Earth and Planetary Science Letters, 363, 44.49 } \\
\text { https://doi.org/10.1016/.epsl.2012.12.031 }\end{array}$ \\
\hline Issue Date & 2013.02 \\
\hline Doc URL & http:/hdl.handle.net/2115/51362 \\
\hline Rights & Copyright $\odot 2012$ Elsevier B.V. A Il rights reserved \\
\hline Type & article (author version) \\
\hline File Information & acceleration.pdf \\
\hline
\end{tabular}

Instructions for use 
Earth Planet. Sci. Lett., 363, 44-49, doi:10.1016/j.epsl.2012.12.031, 2013

\title{
Accelerated Pacific Plate Subduction Following Interplate Thrust Earthquakes at the Japan Trench
}

\author{
Kosuke Heki* \& Yuta Mitsui \\ Dept. Natural History Sci., Hokkaido University, N10 W8, Kita-ku, Sapporo 060-0810, Japan \\ *corresponding author (heki@mail.sci.hokudai.ac.jp, TEL/FAX: +81-11-706-3826)
}

\begin{abstract}
Interplate thrust earthquakes are usually followed by afterslips, and they let the fore-arc move slowly trenchward. However, we do not know if the subducting oceanic plate is accelerated landward after such earthquakes. The westward velocity of Global Positioning System (GPS) stations in NE Japan show gradient decreasing from east to west reflecting the E-W contractional strain built up by the inter-plate coupling. Here we show that such coupling significantly enhanced ( 1.5 times) after the 2003 Tokachi-Oki earthquake $\left(\mathrm{M}_{\mathrm{w}} 8.0\right)$, Hokkaido, in the segments adjacent to the ruptured fault. The coupling seems to be further enhanced ( 3 times) after the 2011 Tohoku-Oki earthquake $\left(\mathrm{M}_{\mathrm{w}} 9.0\right)$. It is unlikely that interplate friction suddenly increased over such a large region, and relatively strong pre-2003 coupling there would not allow such enhancements even if full coupling is attained. Hence they are attributable to the temporary acceleration of the Pacific Plate subduction. We propose a simple 2-dimensional model in which down-dip acceleration of the slab let the force balance rapidly recover promoted by a thin low-viscosity layer on the slab surface. The accelerated subduction would account for temporary activations of regional interplate seismicity after megathrust earthquakes.
\end{abstract}

\section{Introduction}

Space geodetic observations found that current plate motions are not so different from averages over a geological time scale (e.g. Sella et al., 2002), such as those predicted by the NUVEL-1 model (DeMets et al., 1990). Plate motion $\sim 3$ times as fast as the geological average was found in NE Iceland by GPS campaigns (Foulger et al., 1992), and was interpreted as the diffusion of an episodic plate divergence from the plate boundary (e.g. Heki et al., 1993). Anderson (1975) hypothesized that accelerated plate subduction may occur in convergent plate boundaries after a decoupling (large interplate) earthquake and it propagates along trenches by stress diffusion (Bott and Dean, 1973).

Observations with the Japanese dense GPS array revealed that silent fault slips follow large 
interplate thrust earthquakes (Heki et al., 1997; Miyazaki et al., 2004; Ozawa et al., 2011). They realize accelerated trenchward movement of the landward side (i.e. island arc) of the plate boundary. Accelerated landward movement of the oceanic side (including both ocean floor and slab) has been suggested by changes of focal mechanisms of earthquakes within oceanic plates. For example, Lay et al. (1989) found changes from trench-normal compression to tension in outer rise regions, and from down-dip tension to compression in intermediate depths, after megathrust events. However, landward acceleration of oceanic plates immediately after decoupling earthquakes has never been confirmed geodetically due to the scarcity of appropriate islands on oceanic plates near trenches.

The accelerated subduction might be indirectly recognized as the increase of interplate coupling, or accelerated westward interseismic crustal movements in NE Japan. However, ruptured plate interface remains decoupled for years (i.e. afterslip continues) and terrestrial GPS stations above a decoupled portion cannot sense the accelerated subduction. Accelerated convergence is often recognized as the increase of small repeating earthquakes (Uchida et al., 2003), but we cannot tell what fraction comes from the slab acceleration. However, if such acceleration occurs at a relatively large scale (i.e. larger than the rupture zone), there might be changes in the landward crustal movements in adjacent segments where coupling continues. In this study, we utilize the dense array of GPS stations in Japan to investigate such changes associated with the two recent large interplate earthquakes at the Japan Trench, i.e. the 2003 Sep. 26 Tokachi-Oki and the 2011 Mar. 11 Tohoku-Oki earthquakes.

\section{Changes in crustal movements in 2003}

\subsection{Decoupling in the Tokachi-Oki and Tohoku-Oki segments}

GPS stations in NE Japan show landward interseismic movements. Such velocities are proportional to the product of the subduction rate and inter-plate coupling. Because the former is fairly uniform in NE Japan, faster velocity would reflect stronger coupling. Occasional interplate earthquakes let these points jump trenchward, often followed by slow trenchward movements lasting for years or decades caused by afterslip and viscous relaxation (Wang et al., 2012). We divide the plate boundary in NE Japan into four segments, from north to south, 1: Nemuro-Oki (this implies "off the coast of Nemuro"), 2: Tokachi-Oki, 3: Aomori-Oki (including northern Iwate-Oki), and 4: Tohoku-Oki (composed of southern Iwate-Oki, Miyagi-Oki and Fukushima-Oki). They correspond to four distinct offshore asperities separated from each other by weakly coupled regions, and relatively stable interseismic deformation continued until 2003 in all these segments (e.g. Hashimoto et al., 2009). Because interseismic vertical movements in NE Japan cannot be modeled simply with the interplate coupling (Heki, 2004), here we discuss only horizontal components. 
Fig. 1 shows the trenchward movements of the four GPS stations at Nemuro, Taiki, Kuji and Soma, selected as the sensors of coupling in Segments 1, 2, 3, and 4, respectively. The daily position data are taken from the F3 solution of the Japanese GPS array (Nakagawa et al., 2009). We fixed the Kamitsushima station, NW Kyushu, as the reference. Long-term trends inferred from the pre-2003.0 part are removed to isolate post-2003.0 changes in trend. The 2003 Tokachi-Oki and 2011 Tohoku-Oki earthquakes ruptured Segments 2 and 4, respectively. Large coseismic movements of the two earthquakes are removed in Fig. 1a for visual clarity.

In Taiki (Segment 2), we can see long-lasting afterslip of the 2003 earthquake that has not ended (positive slope remains) by the time of the 2011 earthquake. Similar decoupling is seen in Soma (Segment 4). There, the coupling shows weakening since 2003. Unlike afterslips, the positive slope does not decay but show slight increase suggesting progressive weakening of the coupling. This movement is caused by a series of M7 class earthquakes, i.e. the 2003, 2005, 2011 Miyagi-Oki events $\left(M_{w} 6.8,7.2\right.$, and 7.3), the 2008 Ibaraki-Oki event $\left(M_{w} 6.9\right)$, and the 2008, 2010 Fukushima-Oki $\left(\mathrm{M}_{\mathrm{w}} 6.7\right.$ and 6.2) events, and their disproportionally large afterslips. These events are ruptures of relatively small asperities occurred in the course of a large aseismic slip preceding the 2011 Tohoku-Oki earthquake (Ozawa et al., 2012).

\subsection{Enhanced coupling in the Nemuro-Oki and Aomori-Oki segments}

Segments 1 and 3 remain coupled throughout the studied period. In Segment 3, Kuji showed a sudden increase of coupling in 2003 September as seen by a clear break in the slope. The coseismic displacement of the 2003 Tokachi-Oki earthquake was insignificant there and its afterslip cannot explain such a long-term change in trend. Ozawa et al. (2007) attributed it to the abrupt termination of the afterslip of the 1994 Sanriku earthquake (Heki et al., 1997). However, this is unlikely because this afterslip seems to have finished by 1998 (see Fig. 16.10a of Heki, 2007). Nemuro, in Segment 1 , also shows a negative change in trend in 2003. Temporary weakening of the coupling by slow slip events is frequently seen throughout the world, but such a sudden enhancement episode has not been reported so far.

The coupling enhancement at Segments 1 and 3, and the decoupling at Segment 2, appear to have occurred simultaneously, which suggests that the both were caused by a single event, the 2003 Tokachi-Oki earthquake. Although not included in the figure, the farther north-eastern segment (middle of the Kuril Islands) has been decoupled since the 2006 November $\mathrm{M}_{\mathrm{w}} 8.2$ earthquake (Steblov et al., 2010). The decoupling in Segment 4 started with the 2003 October $\mathrm{M}_{\mathrm{w}} 6.8$ Miyagi-Oki event (Ozawa et al., 2012), but its causal relationship with the 2003 September Tokachi-Oki event is not clear.

Fig.2 shows the distribution of the velocity anomalies of GPS stations averaged over 2008.7-2011.0 in NE Japan derived as the difference from the pre-2003.0 velocities. Landward and 
trenchward velocity anomalies are clear in Segments 1, 3 and 2, 4, respectively. It is unlikely that seismic waves suddenly increased interplate friction over such a large region. Coseismic decrease in pore pressure in the plate interface might have increased the friction there. However, the pre-2003 inter-plate coupling is relatively high (Hashimoto et al., 2009; Loveless and Meade, 2010) except the boundary between Segments 3 and 4 (Ye et al., 2012), and it is difficult to attain the landward velocity anomaly by simply increasing the inter-plate friction. We hence hypothesize that the decoupling at Segments 2 and 4 temporarily accelerated the subduction of the Pacific Plate over a multi-segment scale in NE Japan and enhanced coupling in Segments 1 and 3.

Fig. 2c shows raw (i.e. before de-trending) time series of the trenchward movements of three stations in Segment 3 relative to a station on the Japan Sea coast. Their slopes signify the trench-normal shortening rate of NE Japan in Segment 3. By comparing the post-2003 and the pre-2003 shortening rates, we can infer the increase of the plate convergence rate as $\sim 1.5$ times.

\section{Discussion}

\subsection{A simple two-dimensional model}

The acceleration can be understood as the recovery of balance of down-dip and up-dip forces exerted on the subducting slab (Fig.3, rewritten from Seno (2001)). The former is represented by the slab-pull Fsp (and additional ridge push Frp) and is stationary in time scales we are discussing. The latter includes viscous traction on the slab surface Fsr and frictional resistance $F_{c}$ caused by interplate coupling. Fsr scales with the velocity $u$, and the plate-wide balance of these forces determines the time-averaged value of $u$. A decoupling earthquake locally reduces $F \mathrm{c}$ to $F c^{\prime}$ ' $F \mathrm{c}>$ $\left.F c^{\prime}\right)$, and the downward forces would temporarily exceed the friction and let the slab accelerate from $u$ to $u^{\prime}$ ( $u<u$ ') until the viscous braking ( $F$ sr becomes $F$ sr', where $F s r<F s r$ ') realizes the new equilibrium. Actually, oceanic plates are not rigid, and elastic stress in lithosphere between the accelerated and the non-accelerated parts of the plate would grow linearly with time. Although it would be negligible at the beginning, it may emerge as additional braking force and contribute to terminate the accelerated subduction along with the recovery of the interplate coupling Fc. It would be important to investigate what governs the size of the accelerated part of the slab.

Two quantitative issues need to be addressed to validate the hypothesis, i.e. the time constant and the amount of the acceleration. The time series (Fig.1a) suggests that the adjustment occurred within a few months. Average viscosity of the upper mantle beneath NE Japan of $\sim 10^{19} \mathrm{~Pa}$ s (Thatcher et al., 1980) predicts the Maxwell time of tens of years. Therefore, the viscosity of the material responsible for the observed acceleration should be 2 orders of magnitude smaller. Recent laboratory (Hilairet et al., 2007) and seismological (Kawakatsu and Watada, 2007) studies suggested the existence of such layers (water-rich layer) on the upper surfaces of the subducting slab. Thin low-viscosity layers rich 
in melt have also been suggested on the lower boundary (lithosphere-asthenosphere boundary) (Kawakatsu et al., 2009). Such thin low-viscosity layers on the subducting slab surface may enable such a rapid adjustment.

Let us quantitatively examine the 2-D model (Fig.3). If the stress drop and the fault width of the 2003 Tokachi-Oki earthquake was 3 MPa (Kanamori and Anderson, 1975) and 100 km, respectively, the lost up-dip force $\left(F \mathrm{C}-F \mathrm{C}^{\prime}\right)$ would be $3 \times 10^{11} \mathrm{~N} / \mathrm{m}$. Here we roughly assume $1 \times 10^{11} \mathrm{~N} / \mathrm{m}$ as its average over the four segments. Because the slab pull and ridge push cannot change, the accelerated subduction would compensate the lost force by increasing the viscous traction, that is,

$$
F \mathrm{C}-F \mathrm{C}^{\prime}=F \mathrm{sr}^{\prime}-F \mathrm{sr}=\mu\left(u^{\prime}-u\right) W / d .
$$

There $W$ is the total trench-normal length of the slab surface (both upper and lower surfaces) where viscous braking works. The viscosity and the thickness of the low-viscosity layer are $\mu$ and $d$, respectively. If we assume $10^{17} \mathrm{~Pa}$ s for $\mu, 4 \mathrm{~cm} /$ year for $u^{\prime}-u$, and $1 \times 10^{11} \mathrm{~N} / \mathrm{m}$ for $F \mathrm{c}^{\prime}-F \mathrm{c}$, then $W / d$ should be $\sim 800$. This could be realized by, e.g., $800 \mathrm{~km}$ for $W$ and $1 \mathrm{~km}$ for $d$, realistic values for the Pacific Plate slab beneath NE Japan.

\subsection{Change in trench-parallel component}

Although not considered in the model described above, small but significant changes in the trench-parallel component were found in addition to the trench-normal acceleration. Fig.4a shows such movement toward N20E (perpendicular to the component shown in Fig.1a) at points lined up across and along the arc in the segment 3 (Fig.4b). Negative slopes (i.e. movement toward S20W) are seen to appear shortly after the 2003 Tokachi-Oki earthquake. These additional vectors result in counterclockwise deflection of the crustal velocities shown in Fig.2b by as much as $\sim 8$ degrees.

It is not clear whether such deflection reflects that of the subducting slab or a crustal response to the differential subduction underneath. Anyway, we need a 3-D model based on, e.g. the finite element method, for quantitative treatments. Because stations in Segment 1 are too close to the 2003 Tokachi-Oki rupture area, it was unclear if movements of the eastern Hokkaido deflected clockwise.

Existence of this component suggests an alternative possibility that could explain the enhanced coupling in Segment 3 without the slab acceleration, i.e. counterclockwise rotation of the crustal block about a vertical axis pinned to the slab with interplate coupling. There the rotation could have been driven by trenchward velocity anomaly in Segment 4 started in 2003. However, such a block rotation model cannot account for the post-2011 excess coupling seen in Miyagi-Oki by sea floor geodesy discussed in the next section.

\section{Changes in crustal movements in 2011}


The $M_{w} 9.02011$ Tohoku-Oki earthquake should have further accelerated the subduction of the Pacific Plate. In fact, Fig.1a suggests that the post-2011 trend of Taiki turned to negative relative to the pre-2003 value. However, the acceleration signature is difficult to see at the moment because a very fast afterslip goes on over an extensive area (Ozawa et al., 2012). The eastern Hokkaido stations are not much influenced by the afterslip although they showed a few $\mathrm{cm}$ of coseismic jumps (Heki, 2011). Fig.5a shows that accelerated landward movements occur there after the 2011 event. Time series in Fig.5b show nearly constant velocities (i.e. little temporal decay) after the jump. This ascertains that it is not caused by the afterslip of the 2011 event, which should show decay with the time constant of 0.4 year (Ozawa et al., 2012).

The ocean bottom geodetic benchmark MYGI is located close to the epicenter of the 2011 Tohoku-Oki earthquake. This point has been monitored since 2002 and was found to move landward by $8.5 \mathrm{~cm} / \mathrm{yr}$ (Fujita et al., 2006). Sato et al. (2011) reported its coseismic trenchward movement of 24 m by the 2011 earthquake. MYGI was re-occupied 5 times in 10 months after this earthquake (Japan Coast Guard, 2012). The result shows fairly stable landward movement, suggesting that the interplate coupling has already recovered in the fault patch around the hypocenter. Its rate ( $\sim 28.8$ $\mathrm{cm} / \mathrm{yr}$ ), however, far exceeds the time-averaged plate convergence rate there, and cannot be explained without assuming significant slab acceleration. Because this landward velocity is $\sim 3$ times as fast as the pre-earthquake velocity, the Pacific Plate might have been subducting $\sim 3$ times as fast as the long-term average since the 2011 Tohoku-Oki earthquake. This also means unprecedentedly fast crustal shortening between the epicenter and the nearest coast ever recorded geodetically.

The joint sea floor geodesy team of the Japan Coast Guard and the Tohoku University has already started to measure the movement of a densified network of sea floor benchmarks in this area. The network even includes a point beyond the trench axis, and we will hopefully get the direct evidence of the accelerated subduction in a near future.

\section{Concluding remarks}

We here presented the first geodetic data suggesting the accelerated plate subduction after large interplate thrust earthquakes. One important question whose answer is not readily available is the spatial and temporal extent of the acceleration. The nearest GPS point on the Pacific Plate (Marcus Island, $2000 \mathrm{~km} \mathrm{SE}$ of the Tohoku District) has not shown recognizable change in trend after the 2011 event. The acceleration may therefore remain within the vicinity of NE Japan and southern Kuril at this moment. The plate interface may heal eventually, and the time-average rate will then resume. However, the decay of the accelerated movement has not emerged yet, as suggested by the linear post-2003 time series of Kuji in Fig.1a. Hence the time constant of such resumption might be 
somewhat longer than afterslips. Apart from that, as suggested by Pollitz et al. (1998), the accelerated portion of the Pacific Plate may propagate across the Pacific Basin over the next tens of years.

A mega-thrust earthquake often causes regional enhancement of interplate seismicity, e.g. 2004 Sumatra-Andaman earthquake ( $\left.M_{w} 9.2\right)$ was followed by the 2005 Nias $\left(M_{w} 8.6\right)$ and 2007 Bengkulu $\left(M_{w} 8.5\right)$ earthquakes. Such cases have been interpreted in terms of the changes of static stress (e.g. Toda et al., 2011). The regional acceleration of subduction might offer a better explanation especially for cases of successive ruptures of remote segments with locked (i.e. not ruptured) segments in between, e.g. the 2003 Tokachi-Oki, the 2006 Kuril and the 2011 Tohoku-Oki earthquakes. The acceleration may also account for the long-period fluctuation of the rate of seismic energy release as represented by the enhancement during 1950-1965 in the northern and northwestern Pacific Rim (Kanamori, 1977).

Acknowledgements: We thank Geospatial Information Authority of Japan (GSI) for the GEONET GPS data. We also thank Jack Loveless (Smith College) and Marcos Moreno (GFZ-Potsdam) for constructive and thoughtful reviews.

\section{References}

Anderson, D. L., 1975. Accelerated plate tectonics. Science 187, 1077-1079.

Bott, M.H.P, Dean, D. S., 1973. Stress diffusion from plate boundaries. Nature 243, 339-341.

DeMets, C., Gordon, R.G., Argus, D.F., Stein, S. Current plate motions. Geophys. J. Int. 101, 425-478.

Foulger, G.R., Jahn, C.-H., Seeber, G., Einarsson, P., Julian, B.R., Heki, K., 1992. Post-rifting stress relaxation at the divergent plate boundary in Northeast Iceland. Nature 358, 488-490.

Fujita, M., Ishikawa, T., Mochizuki, M., Sato, M., Toyama, S., Katayama, M., Kawai, K., Matsumoto, Y., Yabuki, T., Asada, A., Colombo, O.L., 2006. GPS/Acoustic seafloor geodetic observation: Method of data analysis and its application. Earth Planets Space 58, 265-275.

Hashimoto, C., Noda, A., Sagiya, T. \& Matsu’ura, M., 2009. Interplate seismogenic zones along the Kuril-Japan trench inferred from GPS data inversion. Nature Geosci. 2, 141-144.

Heki, K., 2004. Space geodetic observation of deep basal subduction erosion in the Northeastern Japan. Earth Planet. Sci. Lett. 219, 13-20.

Heki, K., 2007. Secular, transient and seasonal crustal movements in Japan from a dense GPS array: Implication for plate dynamics in convergent boundaries. in The Seismogenic Zone of Subduction Thrust Faults edited by T. Dixon and C. Moore, 512-539, Columbia University Press, pp692.

Heki, K., 2011. A tale of two earthquakes. Science 332, 1390-1391. 
Heki, K., Foulger, G.R., Julian, B.R., Jahn, C.-H., 1993. Plate dynamics near divergent boundaries: geophysical implications of postrifting crustal deformation in NE Iceland. J. Geophys. Res. 98, 14279-14297.

Heki, K., Miyazaki, S., Tsuji, H., 1997. Silent fault slip following an interplate thrust earthquake at the Japan Trench. Nature 386, 595-597.

Hilairet, N., Reynard, B., Wang, Y., Daniel, I., Merkel, S., Nishiyama, N., Petitgirard, S., 2007. High-pressure creep of serpentine, interseismic deformation, and initiation of subduction. Science 318, 1910-1913.

Japan Coast Guard, 2012. Seafloor movements by seafloor geodetic observations before and after the 2011 off the Pacific coast of Tohoku earthquake. Report of the coordinating Committee for Earthquake Prediction, Japan 87, Chapter 3-7.

Kanamori, H., 1977. The energy release in great earthquakes. J. Geophys. Res. 82, 2981-2987.

Kanamori, H., Anderson, D.L., 1975. Theoretical basis of some empirical relations in seismology. Bull. Seism. Soc. Am. 63, 1073-1095.

Kawakatsu, H., Watada, S., 2007. Seismic evidence for deep-water transportation in the mantle. Science 315, 1468-1471.

Kawakatsu, H., Kumar, P., Takei, Y., Shinohara, M., Kanazawa, T., Araki, E., Suyehiro, K., 2009. Seismic evidence for sharp lithosphere-asthenosphere boundaries of oceanic plates. Science 324, 499-502.

Lay, T., Astiz, L., Kanamori, H., Christensen, D. H., 1989. Temporal variation of large intraplate earthquakes in coupled subduction zones. Phys. Earth Planet. Interiors 54, 258-312.

Loveless, J. P., Meade, B. J., 2010. Geodetic imaging of plate motions, slip rates, and partitioning of deformation in Japan. J. Geophys. Res. 115, B02410, doi:10.1029/2008JB006248.

Miyazaki, S., Segall, P., Fukuda, J., Kato, T., 2004. Space time distribution of afterslip following the 2003 Tokachi-oki earthquake: Implication for variations in fault zone frictional properties. Geophys. Res. Lett. 31, L06623, doi:10.1029/2003GL019410.

Nakagawa, H., Toyofuku, T. , Kotani, K., Miyahara, B., Iwashita, C., Kawamoto, S., Hatanaka, Y., Munekane, H., Ishimoto, M., Yutsudo, T., Ishikura, N., Sugawara, Y., 2009. Development and validation of GEONET new analysis strategy (Version 4). J. Geogr. Surv. Inst. 118, 1-8. (in Japanese).

Ozawa, S., Suito, H., Nishimura, T., Tobita, M., Munekane, H., 2007. Possibility of recovery of slip deficit rate between the North American plate and the Pacific plate off Sanriku, Northeast Japan. Geophys. Res. Lett. 34, L20308, doi:10.1029/2007GL030477.

Ozawa, S., Nishimura, T., Suito, H., Kobayashi, T., Tobita, M., Imakiire, T., 2011. Coseismic and postseismic slip of the 2011 magnitude-9 Tohoku-Oki earthquake. Nature 474, doi:10.1038/nature10227. 
Ozawa, S., Nishimura, T., Munekane, H., Suito, H., Kobayashi, T., Tobita, M., Imakiire, T., 2012. Preceding, coseismic, and postseismic slips of the 2011Tohoku earthquake, Japan. J. Geophys. Res. B07404, doi:10.1029/2011JB009120.

Pollitz, F. F., Bürgmann, R., Romanowicz, B., 1998. Viscosity of oceanic asthenosphere inferred from remote triggering. Science 280, 1245-1249.

Sato, M., Ishikawa, T., Ujihara, N., Yoshida, S., Fujita, M., Mochizuki, M., Asada, A., 2011. Displacement above the hypocenter of the 2011 Tohoku-Oki earthquake. Science 332, 1395-1395.

Sella, G.F., Dixon, T.H., Mao, A., 2002. REVEL: A model for recent plate velocities from space geodesy. J. Geophys. Res. 107, 2081, doi 10.1029/2000JB000033.

Seno, T., 2001. Basic Plate Tectonics 2, Asakura Shoten, pp. 162. (in Japanese)

Steblov, G. M., Vasilenko, N. F., Prytkov, A.S., Frolov, D. I., Grekova, T.A., 2010. Dynamics of the Kuril-Kamchatka Subduction Zone from GPS Data. Izvestiya, Physics of the Solid Earth 46, 440-445.

Thatcher, W., Matsuda, T., Kato, T., Rundle, J.B., 1980. Lithospheric loading by the 1896 Riku-u earthquake, Northeastern Japan: implications for plate flexure and asthenospheric rheology. J. Geophys. Res. 85, 6429-6435.

Toda, S., Lin, J., Stein, R.S., 2011. Using the 2011 Mw9.0 off the Pacific coast of Tohoku Earthquake to test the Coulomb stress triggering hypothesis and to calculate faults brought closer to failure. Earth Planets Space 63, 725-730.

Uchida, N., Matsuzawa, T., Hasegawa, A., Igarashi, T., 2003. Interplate quasi-static slip off Sanriku, NE Japan, estimated from repeating earthquakes. Geophys. Res. Lett. 30, 1801, doi:10.1029/2003GL017452.

Wang, K., Hu, Y., He, J., 2012. Deformation cycles of subduction earthquakes in a viscoelastic Earth. Nature 484, 327-332.

Ye, L., Lay, T., Kanamori, H., 2012. The Sanriku-Oki low-seismicity region on the northern margin of the great 2011 Tohoku-Oki earthquake rupture. J. Geophys. Res. 117, B02305, doi:10.1029/2011JB008847. 

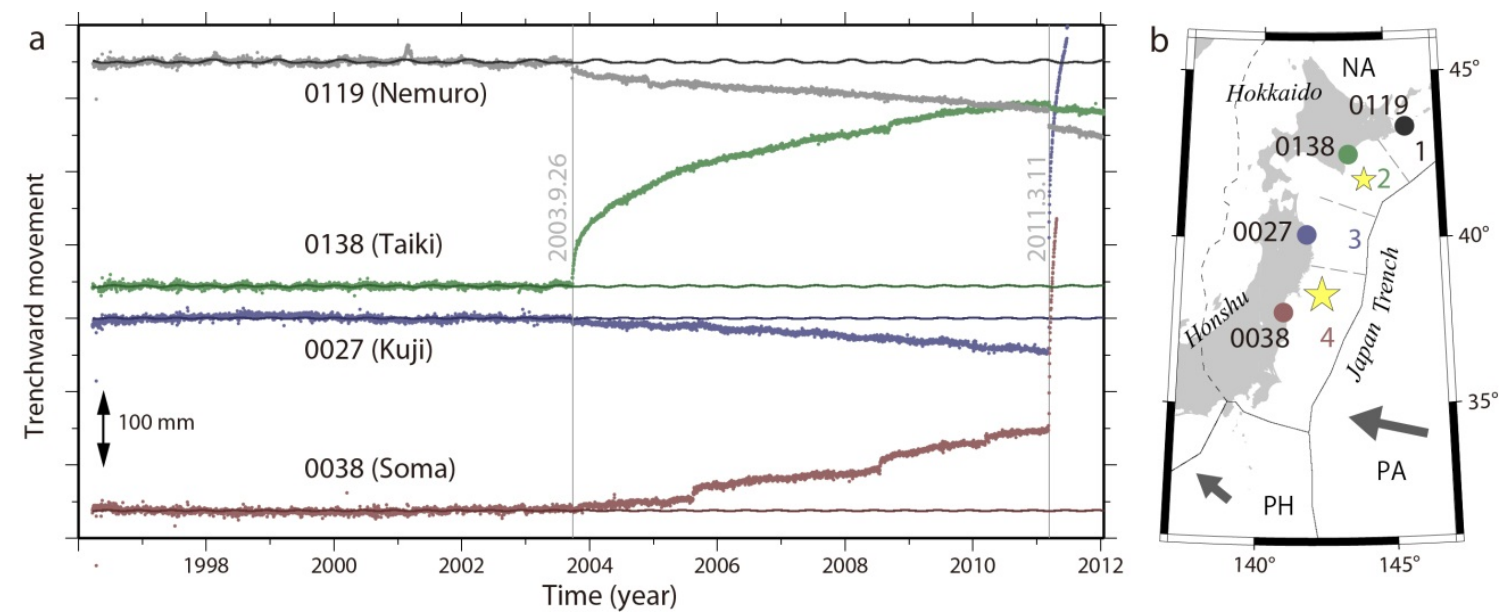

Fig. 1. (a) Trenchward (N110E for 0027, 0038, N150E for 0119, 0138) movement of the four GPS stations, Nemuro (0119), Taiki (0138), Kuji (0027) and Soma (0038), de-trended using the parts before 2003.0 (i.e. linear trend estimated with data up to 2003.0 was removed to isolate post-2003.0 change in trend). In response to the start of upward trends at Taiki and Soma in 2003, downward trends commenced in Nemuro and Kuji. Large coseismic jumps associated with the 2003 and 2011 earthquakes are removed for visual clarity. (b) Plate tectonic setting of NE Japan (PA: Pacific, NA: North America, PH: Philippine Sea), and the four GPS stations shown in (a). Yellow stars show epicenters of the 2003 Tokachi-Oki (small) and the 2011 Tohoku-Oki earthquakes (large). The numbers 1-4 denote the segments of the plate boundary, 1: Nemuro-Oki, 2: Tokachi-Oki, 3: Aomori-Oki, and 4: Tohoku-Oki. The Kamitsushima station (0456), NW Kyushu, was used as the reference. 


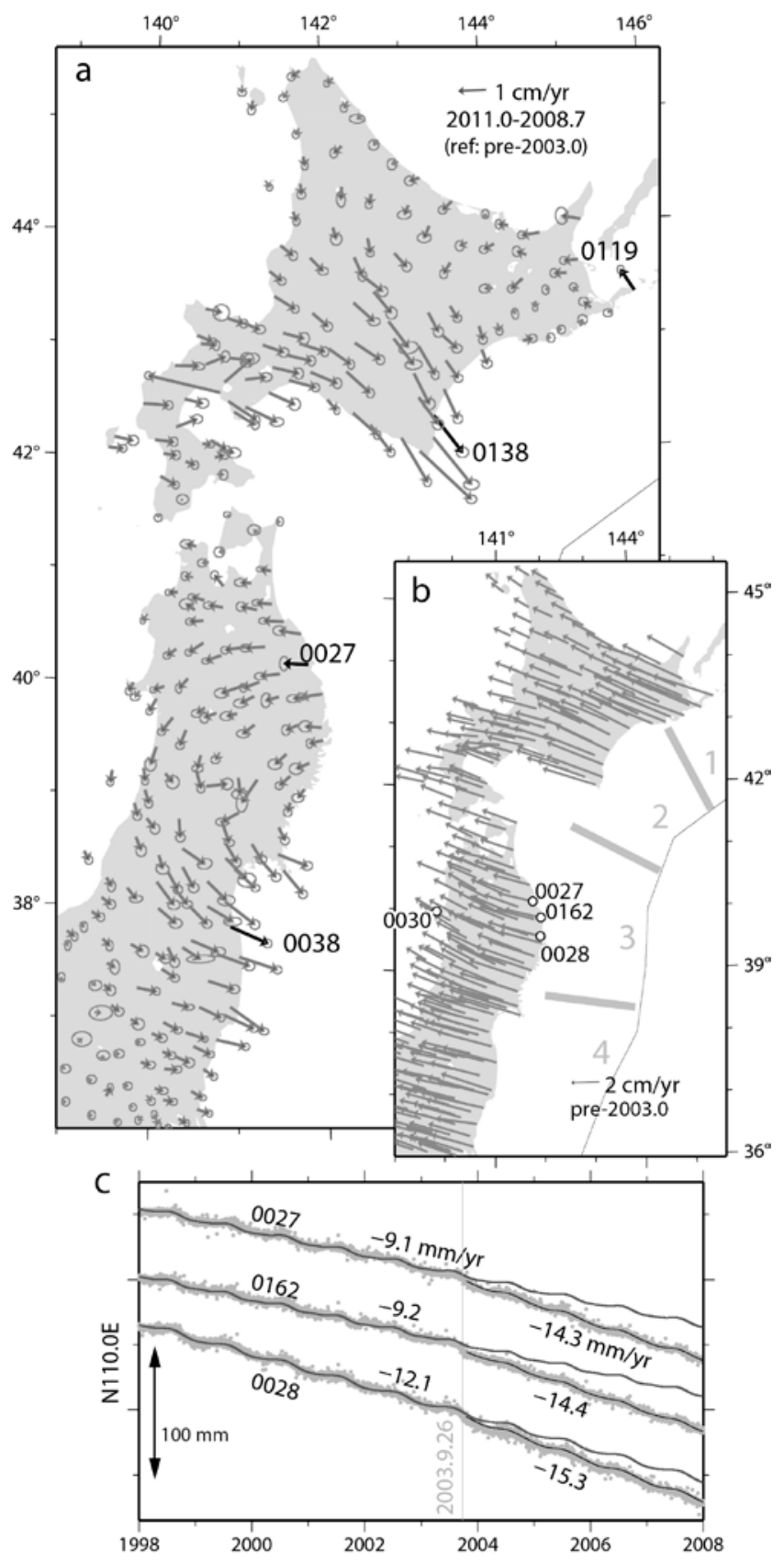

Fig. 2. (a) Differences of the average velocities in 2008.7-2011.0 relative to the reference pre-2003.0 velocities (b). Error ellipses show $1 \sigma$ errors (inferred from standard deviations of coordinates over ten-day periods around the two epochs). The reference station is also 0456. The effect of enhanced coupling is clearly seen in Segments 1 (Nemuro-Oki) and 3 (Aomori-Oki). Black arrows indicate GPS stations shown in Fig. 1. (c) Comparisons of the trenchward velocities (relative to 0030, Oga) of three east-coast stations in Segment 3 (positions shown in b) before and after the 2003 Tokachi-Oki earthquake. 
a Before earthquake

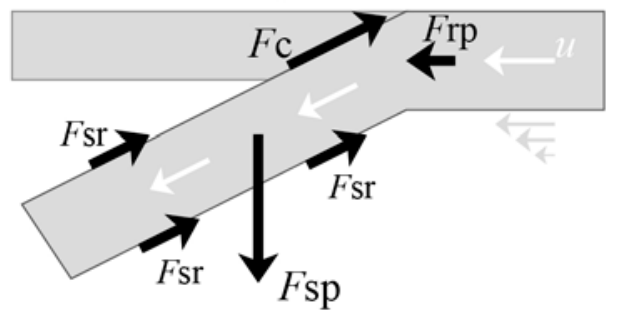

b After earthquake

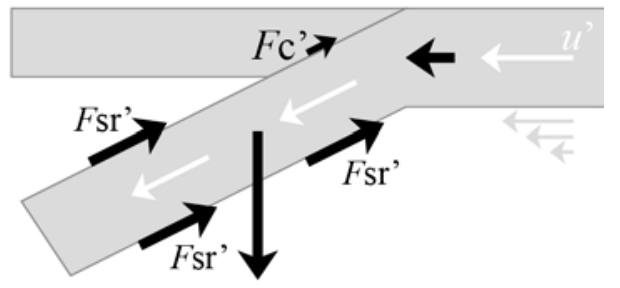

Fig. 3. Schematic diagram of forces acting on the subducting slab before (a) and after (b) a decoupling earthquake. Downward forces (Fsp: slab pull, Frp: ridge push) are balanced by upward forces ( $F$ c: interplate coupling, $F$ sr: side resistance). Sudden decrease of $F \mathrm{c}$ to $F c^{\prime}$ results in the increase of Fsr to Fsr' enabled by the acceleration of $u$ to $u^{\prime}$.

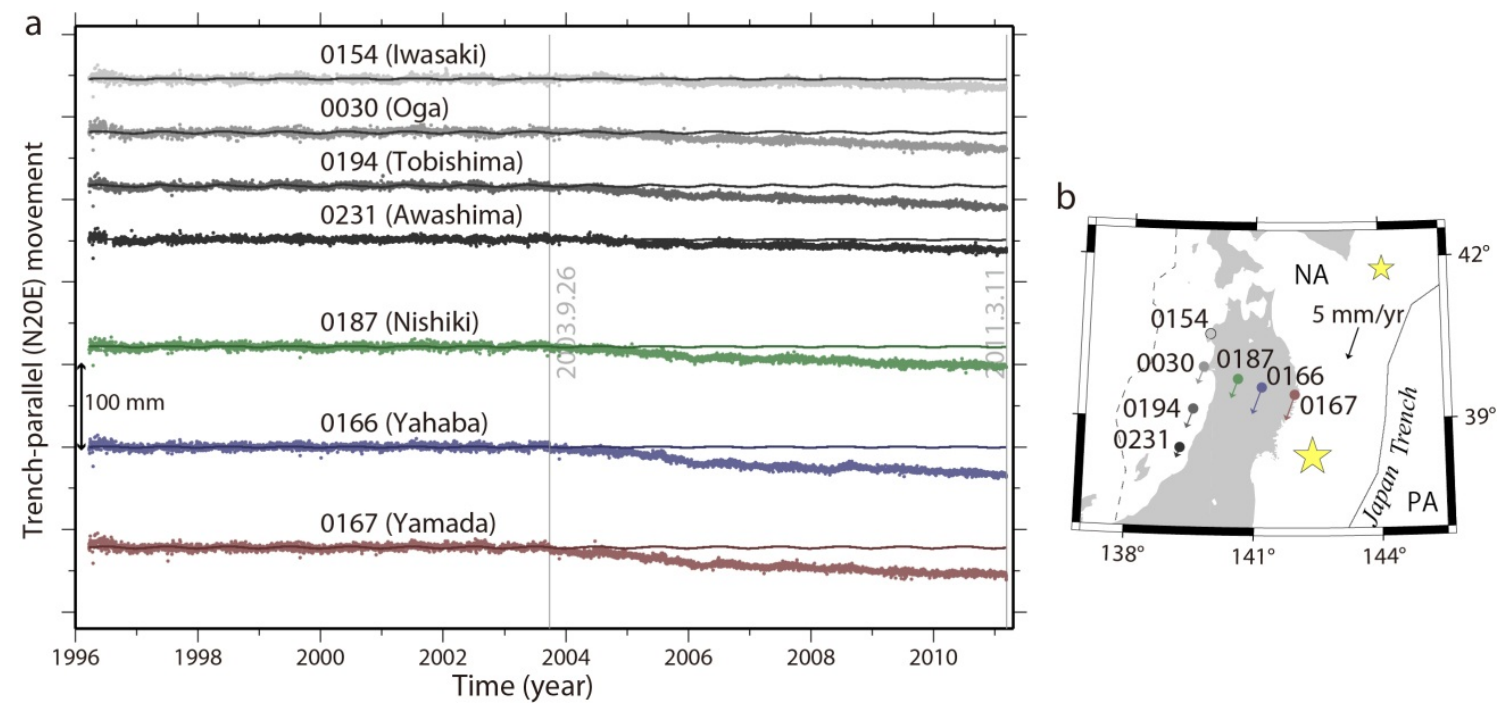

Fig. 4. (a) Trench-parallel (N20E) movement of the seven GPS stations, Yamada (0167), Yahaba (0166), Nishiki (0187), Oga (0030), Iwasaki (0154), Tobishima (0194) and Awashima (0231), de-trended using parts before 2003.5. Trench-parallel movements toward S20W (negative slope) emerge in response to the 2003 Tokachi-Oki earthquake. (b) The seven GPS stations shown in (a) with arrows showing the trench-parallel velocities during 2003.8-2011.1. Yellow stars show epicenters of the 2003 Tokachi-Oki (small) and the 2011 Tohoku-Oki earthquakes (large). 


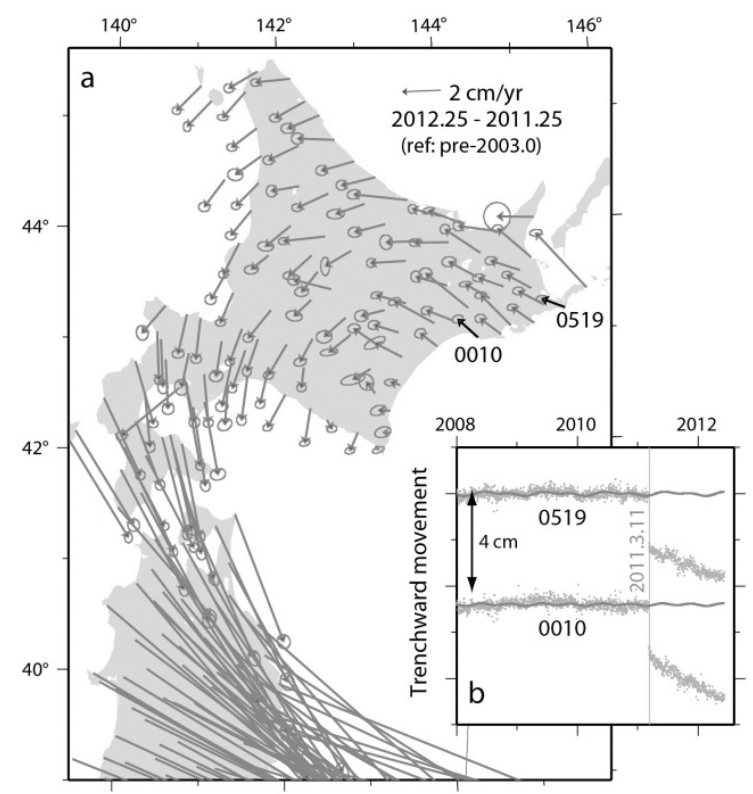

Fig. 5. (a) Differences of the velocities after the 2011 Tohoku-Oki earthquake (during 2011April-2012 March) relative to the reference pre-2003 velocities (Fig.2b). Definition of the error ellipses is the same as Fig. 2. The effect of enhanced coupling is clearly seen in the Nemuro-Oki (Segment 1) and possibly in Tokachi-Oki (Segment 2), but the afterslip signature makes it difficult to see the Aomori-Oki (Segment 3). Arrows with black color indicate two GPS stations whose trenchward (N150E) movements given in (b) show enhanced coupling (accelerated landward movement) after the 2011 event. The reference station is 0456 in NW Kyushu. 